\title{
POR UMA EDUCAÇÃO DEMOCRÁTICA: elaborando uma análise do "Programa Escola sem Partido" a partir do pensamento de Paulo Freire
}

Hosana do Nascimento Ramôa

Resumo

O presente artigo tem como objetivo alinhavar o pensamento de Paulo Freire à atual inquietação sobre a viabilidade da composição de uma Educação Democrática e possível. Partimos de uma análise crítica do posicionamento conservador, com base no "Programa Escola sem Partido", para desenhar um entendimento de suas propostas para a educação. Em seguida, assinalamos elementos para a composição de uma amálgama entre Democracia e Educação, no intuito de cunhar uma visão, junto à Freire, de uma Educação Democrática que responda de maneira coerente aos anseios do exercício educacional, diante de visões embrutecidas do papel da escola e dos professores. Norteando nossa discussão, perguntamos, a democracia se apresenta como orientação possível e realizável dentro e fora do ambiente escolar, diante de proposições conservadoras de educação? Com base em nossa investigação, inferimos que a possibilidade de uma Educação Democrática caminha junto ao questionamento da realidade e a desnaturalização das relações sociais, buscando a cidadania plena, crítica e dialógica.

Palavras-chave: educação democrática; escola sem partido; conservadorismo; paulo freire.

FOR A DEMOCRATIC EDUCATION: elaborating an analysis of the "Programa Escola sem Partido" based on Paulo Freire's thought

\begin{abstract}
This article has the objective to connect Paulo Freire's thought to the current concern about the feasibility of the composition to a possible Democratic Education. We started from a critical analysis of conservative positioning, based on the "Programa Escola sem Partido", to draw an understanding of their proposals for education. Next, we specify elements to the composition of an amalgam between Democracy and Education, to coin a vision, together with Freire, of a Democratic Education that responds consistently to the longings of the educational exercise, in the face of gross visions of the role of the school and teachers. Guiding our discussion, we ask, would democracy be a possible and realizable orientation inside and outside the school space, face of conservative education propositions? Based on our investigation, we infer that the possibility of a Democratic Education walks together the questioning of reality and the denaturalization of social relations, seeking a critical, dialogic and full citizenship.
\end{abstract}

Keywords: democratic education; escola sem partido; conservatism; paulo freire.

\section{POR UNA EDUCACIÓN DEMOCRÁTICA: elaborando un análisis del "Programa Escola sem Partido" a partir del pensamiento de Paulo Freire}

Resumen

Este artículo tiene como objetivo alinear el pensamiento de Paulo Freire con la preocupación actual sobre la viabilidad de la composición de una Educación Democrática y posible. Partimos de un análisis crítico del posicionamiento conservador, basado en el "Programa Escola sem Partido", para llegar a una comprensión 
de sus propuestas de educación. En seguimiento, señalamos elementos para la composición de una amalgama entre Democracia y Educación, con el fin de componer una visión, junto con Freire, de una Educación Democrática que responda consistentemente a los anhelos del ejercicio educativo, ante visiones groseras del papel de la escuela y de los profesores. Conduciendo nuestra discusión, hacemos la pregunta, ¿la democracia se presenta como una orientación posible y alcanzable dentro y fuera del espacio escolar, frente a las propuestas educativas conservadoras? A partir de nuestra investigación, inferimos que la posibilidad de una Educación Democrática camina junto con el cuestionamiento de la realidad y la desnaturalización de las relaciones sociales, buscando una ciudadanía plena, crítica y dialógica.

Palabras clave: educación democrática; escola sem partido; conservadurismo; paulo freire.

\section{INTRODUÇÃO}

"O borizonte que nos apresenta ainda é o de mudar o mundo." (ALVES, 2010, p. 159).

A citação acima faz parte de um texto de Claudia Alves (2010). Nele, a autora menciona a obra de Paulo Freire, destacando seu compromisso na construção de uma Educação voltada para os sujeitos de hoje e do amanhã. Alves (2010) acentua a importância do trabalho de Freire, apontando sua ação política, somada ao "[...] magistério, coordenação, extensão e, sobretudo, reflexão de uma prática voltada para a educação dos trabalhadores” (ALVES, 2010, p. 158) ${ }^{1}$.

Demonstrando - mediante suas reflexões em torno da obra de Freire -, que o ato de educar envolve cidadania, luta e historicidade, a autora aponta para a escolha que precisamos fazer, e que grita no trabalho de Freire: entre "a acomodação fatalista" ou "a crítica ética" (ALVES, 2010, p. 160). A opção selecionada provoca um posicionamento que vai perpassar toda a vida do sujeito. Isso significa que nossas atitudes estarão ao lado dos dominantes, que propagam seus próprios interesses e desafetos ou junto daqueles que lutam por uma vida melhor, dignidade e respeito.

Deixando-nos a mensagem de que necessitamos nos posicionar, Paulo Freire (2018) vem sendo alvo de inúmeros ataques e tentativas de desqualificação no cenário brasileiro atual. Essas iniciativas, podemos dizer, são um reflexo do forte impulso conservador que atravessa nosso cotidiano e pode ser percebido nos noticiários, em projetos de lei e na narrativa coletiva, seja pelos que apoiam ou por aqueles que se opõem. Neste trabalho, a "onda conservadora" (SEPULVEDA; SEPULVEDA, 2019) figura nas propostas e ideias do "Programa Escola sem Partido" (ESP). É através de suas argumentações que vislumbramos os intentos conservadores para a sociedade, especialmente a educação.

A partir de uma leitura ancorada na necessidade de contribuir para a luta pela liberdade de aprender e ensinar, iniciamos nosso artigo mobilizando as perspectivas sustentadas por Juniele Almeida e Renan Caldas (2017), Ivanilda Figueiredo (2016), Fernando Penna (2018), José Sepulveda e Denize Sepulveda (2019) na elaboração de um entendimento acerca do "Programa Escola sem Partido". Tal opção se deu pela extensa bibliografia destinada a compreender criticamente o movimento. Assim, buscamos não só valorizar os sentidos elaborados pelos autores, mas desenhar um entendimento sucinto do que seria o ESP e suas principais contestações.

\footnotetext{
${ }^{1}$ Muitas das reflexões aqui apontadas foram fertilizadas pelas leituras e debates da disciplina de Teoria e Educação II: Seminários avançados sobre o tema "Intelectuais, Democracia e Educação", ministrada pela Profa. Dra. Claudia Alves, para uma turma de doutorado no Programa de Pós-graduação em Educação na Universidade Federal Fluminense, no ano de 2019. Junto às experiências das aulas, este trabalho também contou o incentivo e as observações da orientação do Prof. Dr. Everardo Paiva de Andrade (Faculdade de Educação/ Programa de Pós-Graduação em Educação, UFF).
} 
Ampliando a reflexão, usamos o programa como uma lente para entender o projeto de educação objetivado pelo movimento conservador para a educação brasileira. Para isso, construímos um diálogo entre as demandas de hoje e o enfoque de Paulo Freire (2018) especialmente suas ideias presentes na obra "Educação como prática da liberdade" (2018) -, para estruturar uma crítica à mecanização da relação professor-aluno e da ótica que entende o processo educacional enquanto um perpetuador da alienação e silenciamento dos debates imprescindíveis à ação democrática.

Confrontando o pensamento conservador do ESP, nos aproximamos da postura de Christian Ingo Lenz Dunker (2019) no tocante à democracia, na segunda parte de nosso texto. A saber, nosso propósito não é apenas o de analisar criticamente o posicionamento conservador, mas fornecer elementos possíveis para a composição de uma amálgama entre Democracia e Educação², e, por conseguinte, uma Educação Democrática que responda de maneira coerente aos anseios do exercício educacional, diante de visões embrutecidas do papel da escola e dos professores.

A menção à concepção democrática de Dunker (2019) abre caminho para o exame de uma ação e vivência democráticas presentes e constituidoras do ato educacional. Fazendo um deslocamento, que consiste no ir e vir, entre as considerações de Paulo Freire (2018) e as ponderações de Dunker (2019), encaminhamo-nos para a terceira parte de nosso trabalho, onde adentramos mais detalhadamente as elucubrações de Freire (2018) para uma Educação Democrática.

Como uma forma de enfrentar a alienação, objetificação e desumanização de propostas antidemocráticas e antidialógicas para a educação - de seu tempo e do nosso -, o autor nos convida a mergulhar na possibilidade de desenvolvimento de uma Educação que verse pela conscientização e diálogo de práticas e vivências democráticas. Motivando-nos, assim, a reflexionar acerca de uma elaboração de Educação que considere alunos e professores como sujeitos concretos e que assuma o caráter dialógico e democrático das relações educacionais, face às insurreições conservadoras ${ }^{3}$.

A escolha por uma reflexão pautada em aspectos teóricos, mas em constante acordo com questões inflamadas de nosso cotidiano, se justifica pelo desafio de buscar na obra de Freire (2018) caminhos possíveis e realizáveis, não apenas para fazer frente à redução da educação à aspectos inférteis e limitadores, mas, principalmente, para encontrar uma orientação que corrobore para o pleno exercício democrático e educacional. Para tanto, tivemos como principal objetivo alinhavar o pensamento de Paulo Freire à atual inquietação sobre a viabilidade da composição de uma educação democrática e possível.

No ano em que comemoramos o centenário de nascimento do autor (2021), revisitar sua obra, utilizando-a como ferramenta de análise da realidade e, sobretudo, como um meio de veicular e reafirmar uma Educação pautada na Democracia é praticar um ato de resistência e de existência. Posto isto, trazemos como questão de pesquisa a seguinte indagação: A democracia se apresenta

\footnotetext{
${ }^{2}$ Utilizaremos Educação, Educação Democrática e Democracia com letras maiúsculas quando tratarmos de concepções que defendemos, quando for de uma forma geral ou segundo outras perspectivas utilizaremos letra minúscula.

${ }^{3}$ Algumas partes deste artigo foram apresentadas no III Seminário Estado, Trabalho, Educação e Desenvolvimento: para onde vai a Educação? Crise do capital, conservadorismo e desafios à democracia na América Latina (200 anos de Friedrich Engels), realizado de forma online pela Universidade Federal Fluminense, entre os dias 14 e 18 de setembro de 2020. E no $31^{\circ}$ Simpósio Nacional de História: história, verdade e tecnologia, no Simpósio Temático 038, intitulado "Educação democrática e ensino de História: embates políticos, enfrentamento do anti-intelectualismo e dos negacionismos, proposições pedagógicas de caráter emancipador”, realizado de forma online pela ANPUH, entre os dias 19 a 23 de julho de 2021. Alguns pontos da discussão apresentada constam nos Anais dos eventos.
} 
como orientação possível e realizável dentro e fora do ambiente escolar, diante de proposições conservadoras de educação?

\section{PROGRAMA "ESCOLA SEM PARTIDO": UM RETRATO DO PENSAMENTO CONSERVADOR QUE RONDA A EDUCAÇÃO BRASILEIRA}

Aliando o pensamento conservador e a iniciativa de indivíduos que não são da área educacional - mas que insistem em tentar ditar regras para a Educação, seus profissionais e instituições -, optamos por trabalhar com o "Programa Escola sem Partido" (ESP), detalhando algumas de suas ideias. Essa escolha se deve à sua visibilidade e presença no debate público, que, mais do que gerar projetos de lei, tem grande impacto na esfera social, tensionando discussões e pensamentos.

Como argumenta Ivanilda Figueiredo (2016), as propostas de grupos e sujeitos conservadores, não visam, necessariamente, "[...] aprovar um projeto polêmico, mas sim pautar a agenda e inseri-la no debate público" (FIGUEIREDO, 2016, p. 15). Esta é uma de nossas motivações ao abordar o ESP, pois, ele acaba configurando um retrato dos movimentos conservadores brasileiros. Somado a isso, enquanto um discurso capaz de afetar outras dimensões da sociedade, segundo Fernando Penna (2018b), o ESP possui um caráter antidemocrático e antipolítico, o que direciona à construção de um projeto educacional de cunho conservador.

Criado em 2004, o "Escola sem Partido" é definido em seu site oficial, como uma "iniciativa contra o uso das escolas e universidades para fins de propaganda ideológica, política e partidária" (ESCOLA SEM PARTIDO, 2020). Seu argumento principal parte da ideia de que escolas e faculdades (públicas e privadas) são locais utilizados para propagar correntes políticas e ideológicas, sendo os professores, os operadores dessa "doutrinação política e ideológica" em tais espaços (ALMEIDA; CALDAS, 2017, p. 72).

Juniele Almeida e Renan Caldas (2017), traçando uma análise do programa, apontam duas colunas que sustentam seu discurso e que se baseiam na noção de doutrinação: a primeira é referente à relação entre professor e alunos em sala de aula e a segunda envolve o impedimento à discussão de determinadas temáticas.

No primeiro caso, os autores demonstram que o cenário criado pelo ESP para a relação docente-discente é demasiado problemático. Defendendo que os alunos formam uma audiência cativa na sala de aula, eles seriam "[...] vítimas do abuso intelectual e da autoridade do professor" (ALMEIDA; CALDAS, 2017, p. 72). Em contrapartida, os docentes representariam um perigo, pois, caracterizariam um “"sequestrador intelectual' dos seus próprios alunos" (ALMEIDA; CALDAS, 2017, p. 72).

A segunda coluna de sustentação, para Almeida e Caldas (2017), manifesta o embargo à menção de acontecimentos políticos, bem como, a discussão de temáticas como gênero, racismo, homofobia, machismo, dentre outros, em sala de aula. Seguindo essa perspectiva, os professores deveriam se ater a ensinar o conteúdo de sua disciplina, não interferindo com sua opinião, ou mesmo, abordando temas que estão presentes na atualidade e fazem parte do cotidiano de uma vida em sociedade.

Esse tipo de fixação nos adverte acerca do perigo que rodeia a identidade dos professores, uma vez que ela já se encontra ameaçada. De acordo com Fernando Penna (2018a), a atribuição de significados e a leitura que se faz da realidade podem interferir em nossa concepção de escola, professor e aluno: 
Tenho analisado, nos últimos anos, como o discurso reacionário de defesa de uma "escola sem partido" tem tentado fixar esses sentidos: professor - militante disfarçado, abusador, estuprador, sequestrador intelectual, não é educador; aluno - audiência cativa, folha em branco, 'meu filho, minhas regras'; escolarização relação de consumo, instrução, transmissão de conteúdo. Em alguns desses mesmos textos, procurei mostrar como esses sentidos fixados entram em choque com o discurso de defesa de uma "educação democrática": professor - educador, constrói conhecimento no diálogo, mobiliza valores vinculados a uma formação democrática e a uma cultura de direitos humanos; aluno - detentor de saberes, capaz de interpretar e criticar, tem direito à educação; escola - espaço democrático, gestão democrática com a participação da comunidade, construção de conhecimento. (PENNA, 2018a, p. 114)

Penna - que tem se dedicado a pesquisar o discurso reacionário frente ao âmbito educacional desde o ano de 2015 -, nos ajuda a compreender o ESP como um "[...] projeto de escolarização que remove da escola o seu caráter educacional” (PENNA, 2018a, p. 113). Além disso, sua atuação em busca de estratégias que viabilizem uma educação democrática contribui para direcionarmos nosso olhar sobre a obra de Paulo Freire, evidenciando o potencial que ela carrega.

Os elementos citados no trecho acima (escola, professor e alunos), não só constituem o processo de escolarização, mas encontram-se em meio a constantes disputas para estabelecer seus sentidos e suas relações. Essas disputas não são ingênuas, tendo em vista o potencial da Educação de humanizar os sujeitos, propiciando uma "[...] reflexão sobre si mesmo, sobre seu tempo, sobre suas responsabilidades" (FREIRE, 2018, p. 80), contribuindo, ainda, para a desmistificação das relações sociais e para o processo de conscientização.

O que vemos no discurso do "Programa Escola sem Partido", entretanto, é uma tentativa de solapar as potencialidades da Educação e das relações que se estabelecem no espaço escolar. Tendo como base as duas colunas de sustentação citadas por Almeida e Caldas (2017), a intenção do ESP seria reduzir, então, a Educação à uma acumulação de conteúdos desvencilhados da realidade social, política e cultural, o que nos lembra a crítica de Paulo Freire (2019) à uma educação bancária, limitada e distante da experiência existencial dos alunos.

Se para o ESP, alunos são audiência cativa e professores, doutrinadores, não podemos esquecer a crítica de Freire à uma "distorcida visão da educação" (FREIRE, 2019, p. 81). Por mais que o referido autor não estivesse aludindo ao atual programa, não há como negar que ambas as proposições - da educação bancária e do "Programa Escola sem Partido" - compartilham concepções que, resguardadas suas particularidades temporais, políticas e sociais, negligenciam a historicidade dos sujeitos e negam a realidade enquanto processo, entendendo-a como estática, fixa e compartimentada. O resultado, em ambos os casos, ocasiona uma adaptação e aceitação do mundo e de suas desigualdades sociais, junto à uma naturalização das circunstâncias presentes.

Ao tratar o processo educacional e seus profissionais com tanta austeridade, o ESP não está somente buscando delimitar a prática educativa, mas também cerceando a elaboração do livre pensar. Segundo Penna (2018b), essa prática caracteriza o caráter antipolítico do programa, pois consiste na negação ao debate. Ou seja, por meio de um argumento de autoridade, a reflexão de alguma situação da vida comum e cotidiana não se realiza, sendo negada e, portanto, encerrando a discussão (PENNA, 2018b, p. 568).

Além de antipolítico, o Escola sem Partido possui, ainda, um caráter antidemocrático. No trecho citado anteriormente, o professor é comparado a um "[...] militante disfarçado, abusador, estuprador, sequestrador intelectual” (PENNA, 2018a, p. 114). Tal paralelo favorece o aparecimento de um antagonismo, fenômeno esse denominado por Penna de "[...] ódio aos 
professores" (PENNA, 2018a, p. 116), no qual os docentes são tidos como inimigos e com quem, consequentemente, não pode haver diálogo. Caracterizando o perfil antidemocrático do programa, todos que se opõe a ele são "demonizados" (PENNA, 2018b, p. 575), especialmente, os docentes.

É mister enfatizar que essas facetas - o caráter antipolítico e antidemocrático - do "Programa Escola sem Partido" trazem um debate que tem ultrapassado o espaço escolar e perpassado toda a sociedade brasileira. Esclarecendo tal assertiva, Ivanilda Figueiredo (2016) assinala que temos vivenciado o discurso do medo. Isso implica tentativas de mudanças nas leis federais, estaduais e municipais, a censura nas salas de aula, a personificação da figura do inimigo e a interferência da religião na política, configurando, assim, uma ameaça a própria democracia.

Nesse cenário, "[...] o limite entre as convicções pessoais de cada cidadão e suas atitudes para com os demais é constantemente questionado" (FIGUEIREDO, 2016, p. 11). O que nos leva a declarar, que, de maneira semelhante ao que ocorre com os professores - no que concerne à proposta do ESP de silenciamento de pontos de vista morais e filosóficos -, os sujeitos e grupos que defendem direitos humanos, gênero e diversidade sexual são entendidos como inimigos e com quem não se pode dialogar.

Em consonância com o posicionamento descrito, temos na pesquisa de José Sepulveda e Denize Sepulveda (2019), a elucidação acerca do desenvolvimento do movimento conservador, o que nos ajuda a compreender melhor no tocante à Educação. Explicitando que o conservadorismo se reproduz como uma retórica carregada pela capacidade de persuasão, os autores alegam que ao constituir-se como uma narrativa de mundo em contínua disputa, ele carrega uma forte relação com o tradicionalismo. Tal encadeamento, suscita uma marca identitária e social, o que possibilita a um segmento populacional a identificação com seus posicionamentos. O resultado dessa correlação pode ser visto na "defesa da moral e dos bons costumes" por diversos grupos, notadamente o "Programa Escola sem Partido".

Somando as características acima à anti-intelectualidade e à antirracionalidade, Sepulveda e Sepulveda (2019) relatam que o movimento conservador corrobora com uma tendência contrária à ampliação de direitos sociais e o combate a práticas revolucionárias, compondo, desse modo, uma atitude antidemocrática (SEPULVEDA; SEPULVEDA, 2019, p. 875).

Para a manutenção e perpetuação desse pensamento, os autores apontam a Educação como um espaço singular, onde existe a possibilidade de realização de uma reforma moral da sociedade e, consequentemente, a composição de uma ordem social. Nessa prospectiva, professores teriam um papel pré-estabelecido: o de transmissão dessa moralidade e dos valores conservadores. Vemos, assim, porque o "Escola sem Partido" ganhou tanto destaque no debate público: primeiro, porque se alia ao pensamento conservador, sendo, mesmo, um retrato para o entendermos; e, segundo, porque sustenta uma retórica persuasiva que simplifica todo o processo educacional em uma imagem estanque.

Constatamos, portanto, que delimitar a Educação e “demonizar" (PENNA, 2018b, p. 575) aqueles que pensam diferente ou são contra uma proposta, não se resume ao âmbito da sala de aula, antes geram um "efeito cascata" (FIGUEIREDO, 2016, p. 15) tanto no que tange à deliberação legislativa, quanto no meio político e social, acarretando ainda, facetas e atitudes antipolíticas e antidemocráticas. Dessa forma, cabe indagar: como podemos concordar com um projeto de escola, de Educação e de sociedade nitidamente antidemocráticos? A resposta é óbvia: não concordamos. Por isso, defendemos a necessidade de relações sociais e de uma Educação que sejam pautados em experiências democráticas e libertadoras, como propunha Paulo Freire (2018). 
TRAÇANDO ALGUMAS APROXIMAÇÕES ENTRE DEMOCRACIA E EDUCAÇÃO: UMA RESPOSTA AO ESP

Dando seguimento ao nosso debate, não poderíamos deixar de realizar alguns apontamentos abordando a ideia de democracia frente à proposta conservadora do "Programa Escola sem Partido", antes de adentrar o pensamento de Paulo Freire (2018). Nosso intuito, entretanto, não é de traçar um pormenorizado encadeamento histórico, e, muito menos, realizar uma exaustiva discussão que dê conta de perspectivas de democracia. Dialogando com o objetivo deste texto, buscamos uma conversa entre a crítica que versamos páginas atrás e a composição de um olhar, que possibilite vislumbrar na Educação, um espaço para a prática democrática. Para isso, trazemos a compreensão de Christian Ingo Lenz Dunker (2019) acerca da democracia brasileira.

O referido autor adverte que nossa democracia não está pronta, mas sempre em construção. Destarte, o ideal é que nesse processo, cada vez mais, ocorra uma ampliação ao maior número de sujeitos possível. Diante de tal reflexão, temos o panorama feito Gaudêncio Frigotto (2018) que incide na chocante ausência de democracia em diversos momentos da história brasileira. Segundo ele, “[...] fomos um país escravocrata por quase quatro séculos e, mesmo ao longo do século XX, um terço dele foi de ditaduras e os outros dois de democracia restrita e de seguidos golpes institucionais" (FRIGOTTO, 2018, p. 24).

Por mais que a democracia não seja uma caixa com as respostas prontas, sendo necessária sua constituição cotidiana, ela ainda pressupõe um caminho oportuno. Árdua, decerto, mas, uma alternativa possível à proposta do "Programa Escola sem Partido", que para Frigotto (2018), demonstra uma clara investida da naturalização da "[...] face mais violenta e excludente das relações sociais capitalistas e que se expressa na sociedade brasileira historicamente com as marcas do autoritarismo e da violência" (FRIGOTTO, 2018, p. 15) sobre a escola.

Se a democracia se apresenta como orientação possível e realizável dentro e fora da escola, então, ela também é uma perspectiva de futuro (DUNKER, 2019, p. 117). Logo, se pensarmos que Educação e Democracia podem andar de mãos dadas por um futuro melhor, então, também poderíamos elucidar que a Educação também se configura como uma perspectiva de futuro, e como um horizonte capaz de mudança.

Não podemos esquecer, porém, que vivenciamos um momento em que se encontram ameaçados tanto a faculdade de aplicar a razão em espaço público, quanto a utilização da palavra como um modo de resolver problemas e conflitos diante de indivíduos que pensem diferente, adverte-nos Dunker (2019). Isto posto, indagamos, como dizer que temos uma Educação que visa à democracia e à liberdade em meio a "tempos sombrios" (ARENDT, 2008)? Inferimos que, tal como a democracia precisa ser construída cotidianamente, a educação também assim o é pelos professores em suas aulas. São os docentes (os mesmos acusados de abusadores e sequestradores intelectuais pelo ESP), que diariamente já executam atividades que valorizam o diálogo democrático e que compreendem o alunado como detentor da capacidade de interpretar e criticar. Por isso, são o principal alvo do "Programa Escola sem Partido" e de sua proposta conservadora.

"Não existe Estado democrático sem educação democrática" (FERNANDES, 1989, p. 20) já dizia Florestan Fernandes, contudo, que tipo de democracia temos experienciado? Dunker (2019) - ao estabelecer uma reflexão em torno do estado de massa ${ }^{4}$, frente à emergência das mídias digitais e de seu impacto no campo político do Brasil -, nos avisa sobre a encruzilhada vivida pela

\footnotetext{
${ }^{4}$ Segundo Dunker (2019), o estado de massa se caracteriza pela suspensão da ideia de que outras pessoas são sujeitos como nós, os vemos como objetos ou, mesmo, instrumentos, excluindo-os de nosso paradigma de humanidade e racionalidade.
} 
democracia brasileira atualmente. Se por um lado, ela enfrenta uma "democracia de condomínios" ${ }^{5}$ regida por determinados grupos, por outro, vemos uma ampliação da democracia, atingindo um número maior de sujeitos devido o acesso ao mundo digital.

Diante desse cenário, o autor argumenta que, de tempos em tempos, a democracia desordena, altera e reformula o valor dos signos sociais, através dos quais, identificamos se somos sujeitos pertencentes a um determinado grupo ou não. À vista disto, Dunker (2019) estabelece que a cada estágio da democracia, torna-se necessária uma redefinição, seja ela conflituosa ou não, da "lei geral de reconhecimento e sua abrangência para quem atribuímos a condição de sujeito" (DUNKER, 2019, p. 123).

Semelhantemente à ideia de mudança defendida por Dunker (2019) - referente aos signos sociais -, Paulo Freire (2018), argumenta que as sociedades vivem fases de trânsito (FREIRE, 2018, p. 64). Estas fases representam um choque entre os valores de ontem, que se encontram em esvaziamento, e, os valores emergentes do amanhã, que fazem as sociedades entrarem em novos momentos ${ }^{6}$.

Freire (2018) explica o processo de trânsito de uma sociedade fechada ${ }^{7}$ para uma aberta, e, posteriormente, especifica como ela pode se tornar fechada novamente. Distinguindo-as, podemos resumir uma sociedade fechada como aquela que se centra e concerne relevância aos interesses focalizados em "formas mais vegetativas de vida" (FREIRE, 2018, p. 81), como o período de ditadura civil militar no Brasil. Enquanto uma sociedade aberta, trata-se de uma sociedade que começa a se perceber e se conhecer, deixando de ser objeto e se tornando sujeito, assumindo-se e reconhecendo-se como tal.

O que nos interessa nessa movimentação, contudo, é destacar que, diante de uma sociedade fechada ou em processo disso - marcada pelo embrutecimento e discursos de ódio - é a Educação, no entendimento de Freire (2018), que possibilita a humanização do homem. Segundo ele:

[...] esta passagem, absolutamente indispensável à humanização do homem brasileiro, não poderia ser feita nem pelo engodo, nem pelo medo, nem pela força. Mas, por uma educação que, por ser educação, haveria de ser corajosa, propondo ao povo a reflexão sobre si mesmo, sobre seu tempo, sobre suas responsabilidades, sobre seu papel no novo clima cultural da época de transição. Uma educação que lhe propiciasse a reflexão sobre seu próprio poder de refletir e que tivesse sua instrumentalidade, por isso mesmo, no desenvolvimento desse poder, na explicitação de suas potencialidades, de que decorreria sua capacidade de opção. (FREIRE, 2018, p. 80-81)

Pensada por Freire (2018), a Educação se desenrola a partir do próprio sujeito, numa reflexão sobre si, o mundo, sua ação e seu tempo. De maneira semelhante, a democracia ou as ações democráticas só podem acontecer pelos próprios indivíduos, pelo povo e não através de seu consentimento. É pelo pleno exercício democrático e educacional que uma Educação Democrática é possível. E isso implica o reconhecimento de docentes e discentes enquanto sujeitos pensantes e atuantes, concepção distante da estagnada identificação doutrinador-audiência cativa do ESP.

${ }^{5}$ É definida pelo autor como um estado de democracia reduzido, situado entre os muros que protegem alguns indivíduos e afastam a massa segregada.

${ }^{6}$ Ao falar em trânsito e mudança, Freire (2018) não está afirmando que ocorram apenas idas e avanços, vindas e recuos também são ocorrências comuns. Esses recuos, porém, não são capazes de impedir a transição, mas podem gerar confusão e atraso.

${ }^{7}$ Essa definição também se aplica a uma comunidade "intransitivada" ou sociedade alienada, segundo Freire (2018). 


\section{DIALOGANDO COM PAULO FREIRE PARA A CONSTRUÇÃO DE UMA EDUCAÇÃO DEMOCRÁTICA}

Intentar uma Educação Democrática requer ultrapassar a visão política da democracia e compreendê-la enquanto uma forma de vida, permitindo, desse modo, uma legítima participação, alimentando experiências democráticas. Nesse caso, a Educação, enquanto uma propositora de constantes mudanças de atitude, contribuiria para a superação da passividade e o alcance de "[...] novos hábitos de participação e ingerência" (FREIRE, 2018, p. 123-124).

Ao fazer uso do termo "Educação Democrática" (FREIRE, 2018, p. 127), Paulo Freire torna patente que, para conhecer, viver e agir democraticamente é preciso aprender com a própria Democracia, exercendo-a. De maneira semelhante, Penna (2017), estabelece que a aprendizagem da Democracia não ocorre apenas por meio das escolas, mas na vida como um todo. Ou seja, uma Educação Democrática dá-se em todos os espaços e experiências de convivência democrática (PENNA, 2017, p. 254), o que fortalece ainda mais a ideia de que a Democracia é, antes, uma forma de vida.

Compreendendo-a enquanto modo de vida - e de modo análogo à Educação -, Freire (2018) aponta que "[...] a própria essência da democracia envolve uma nota fundamental, que lhe é intrínseca - a mudança" (FREIRE, 2018, p. 119). A respeito disso, o autor acrescenta que os regimes democráticos utilizam-se de termos que são flexíveis e mutáveis, e portanto mudam constantemente, o que o leva a concluir que os sujeitos também precisam ter uma "[...] maior flexibilidade de consciência" (FREIRE, 2018, p. 119). Nesse sentido, para nomear uma Educação como democrática é preciso levar em consideração a problematização e crítica da realidade, somada à uma atenção à responsabilidade política e social e à potencialidade do diálogo, na qualidade de estimuladores da mudança.

Ao estabelecer uma íntima relação entre a Democracia e uma Educação Democrática, Freire (2018) não só aposta na capacidade de mudança, mas também na crença nos sujeitos. Isso significa dizer que, os indivíduos são capazes, mas, sobretudo, precisam e devem discutir seus problemas - sejam estes referentes a seu trabalho, ao seu país, ao mundo ou à própria Democracia -, se desejam uma maior conscientização, como juntamente, a mudança. Frente a essa constatação, o autor tece uma crítica à uma visão de educação que se impõe aos sujeitos, e, que pode muito bem ser usada para pensar a proposta do Programa "Escola sem Partido", bem como, o pensamento conservador que circunda a sociedade brasileira:

Ditamos ideias. Não trocamos ideias. Discursamos aulas. Não debatemos ou discutimos temas. Trabalhamos sobre o educando. Não trabalhamos com ele. Impomos-lhe uma ordem a que ele não adere, mas se acomoda. Não lhe propiciamos meios para o pensar autêntico, porque, recebendo as fórmulas que lhes damos, simplesmente as guarda. (FREIRE, 2018, p. 127)

Sem correr risco de anacronismo, a citação acima nos incita a olhá-la como uma tradução possível para a proposta do ESP, para a acepção conservadora que entrevê no professor uma mera função transmissora de conteúdos e no aluno uma esponja, que absorve sem criticidade, figurando uma "audiência cativa". Obviamente, Paulo Freire (2018) não escreveu seu texto referindo-se ao movimento que surgiu em 2004, porém, sua obra, mais do que permitir vislumbrar o potencial do processo educacional, nos leva a refletir, analisar e, mesmo, levantar críticas às iniciativas que desconsideram as narrativas existenciais dos sujeitos e grupos, convocando-nos a não cair nas armadilhas de uma mecanização da educação. 
Chamando nossa atenção para o distanciamento que existe entre uma educação para "alienação" ou "domesticação" e uma Educação para a "liberdade" (FREIRE, 2018, p. 52), o referido autor nos leva a questionar se este desafio, ainda, se apresenta em nossos dias, afinal, temos enfrentado um discurso de ódio direcionado aos professores que fomentam o raciocínio crítico e lutado contra tentativas de cerceamento da liberdade de ser das diversas identidades e subjetividades nos diferentes espaços, inclusive na escola.

Para Freire (2018), existem forças que encontram na alienação dos sujeitos e da própria sociedade, uma maneira de garantir seus privilégios, concebendo o "aclaramento das consciências" (FREIRE, 2018, p. 53) uma ameaça aos seus interesses. Uma das formas de evitarem esse "aclaramento", e de, simultaneamente, se manterem no poder, perpetuando a alienação de outros grupos, é através de uma distorção da realidade.

Apresentando-se como defensoras dos sujeitos, da liberdade e dignidade, essas forças depreciam a autêntica libertação, imputando-lhe a ideia de "perigosa subversão", "massificação" e "lavagem cerebral", ou, ainda, um "produto de demônios, inimigos do homem e da civilização ocidental cristã" (FREIRE, 2018, p. 53), discurso semelhante a atual "demonização" docente e da "doutrinação" feita nas escolas e universidades.

Sob esse prisma, advogar por uma Educação liberadora e democrática indica a busca por uma conscientização frente aos discursos acima apontados. Em outras palavras, uma Educação que verse para o desenvolvimento dos sujeitos e não para uma alienação ou objetificação. O que possibilitaria uma reflexão de si, de sua inserção no tempo e no espaço, de sua apreensão como agente histórico e protagonista de sua história.

Como ato criador, cujo caráter fecundo pode suscitar outros atos criadores, uma Educação democrática sinaliza e preconiza a ação democrática, tendo no ser humano, não o paciente do processo, mas seu sujeito e ator principal. Esse posicionamento é, por conseguinte, o objetivo da transitividade crítica, ou seja, um "[...] retorno à matriz da verdadeira democracia”" (FREIRE, 2018, p. 84).

Diferenciando a intransitividade da transitividade, Freire (2018) explica que a primeira sugere o ato de não ultrapassar a órbita vegetativa, não enfrentando os desafios e questionamentos que se apresentam fora da zona de conforto. É preciso atentar, entretanto, que a consciência intransitiva de um sujeito não o fecha em si mesmo, pois o ser humano é um ser aberto, mas é inegável que esse tipo de consciência atrapalha o discernimento e acaba limitando a compreensão e entendimento. Em suma, significa a dificuldade em gerar a conscientização e criticidade por parte dos sujeitos.

Em contrapartida, quando o sujeito começa a ampliar seus referenciais, passando a se interessar por assuntos e elementos para além dos domínios da esfera vital e preocupando-se com cenários outros, pode-se dizer que ele passou da intransitividade para uma consciência transitiva. A transitividade envolve "dialogação" (FREIRE, 2018, p. 86) com o mundo e com outros sujeitos, o que viabiliza compreensão e resposta a questionamentos sociais mais abrangentes, além de um comprometimento com a realidade e a existência.

Antes de continuarmos, é necessária uma observação acerca da passagem de uma consciência intransitiva para a transitividade. Ela pode, a princípio, decorrer ingenuamente, levando à uma consciência fanatizada, o que configura uma ameaça. A "consciência transitivo-ingênua" (FREIRE, 2018, p. 86-87) se caracterizaria, então, pela expansão dos horizontes, contudo, teria uma dialogação carregada de teor mágico, que acabaria desviando-a e distorcendo-a. Dessarte, teríamos, ao invés do sujeito crítico e consciente, um sujeito marcado pela irracionalidade, que se negaria ao diálogo e se tornaria desumano (FREIRE, 2018, p. 87). 
Para que uma consciência faça a travessia, deixando de ser transitivo-ingênua e se tornando transitivo-crítica - cuja mentalidade é propriamente democrática - se faz vital a dialogação junto à um mergulho, cada vez mais profundo, do sujeito em sua problemática, exercendo seu poder de escolha e rejeitando os preceitos e prescrições que tentam impor sobre ele. Desse modo, vale dizer que, para a consciência transitivo-crítica o propósito do sujeito “[...] não é coisificar-se, mas humanizar-se" (FREIRE, 2018, p. 87).

Fazendo uma elucidativa caracterização da consciência transitivo-crítica, podemos dizer que ela é voltada para o diálogo, o que denota um posicionamento e responsabilização. Ela implica o despojamento de preconceitos e o distanciamento de deformações nas análises dos problemas, acrescentando princípios causais ao invés de explicações mágicas e irreais. Segundo Freire (2018), seria possível chegar até a transitividade crítica por uma "[...] educação dialogal e ativa, voltada para a responsabilidade social e política" (FREIRE, 2018, p. 84), cujo aspecto principal seria uma dedicada e aprofundada análise e compreensão dos problemas, sejam eles sociais, políticos ou culturais.

A definição da consciência transitivo-crítica de Paulo Freire (2018) se aproxima estreitamente das propostas de Fernando Penna (2018a) e de Gaudêncio Frigotto (2018) para uma Educação Democrática. Face as imposições do pensamento conservador de nossos dias, Frigotto (2018) argumenta em favor de uma Educação que entenda os alunos como sujeitos concretos, levando em consideração suas culturas, condições sociais e realidades em que vivem, e, acrescenta:

$\mathrm{Na}$ ótica de uma educação de qualidade democrática estão implicados, como condição necessária, o acesso ao conhecimento historicamente produzido pela sociedade e a afirmação dos valores coletivos de justiça, solidariedade e cooperação. Em relação ao método, a qualidade democrática da educação implica romper com a visão fragmentária de conhecimento e superar a oposição entre educação geral e específica, humanista e profissional e política e técnica (FRIGOTTO, 2018, p. 26).

Em acordo com a perspectiva do mencionado autor, para Fernando Penna (2018a) é imprescindível uma Educação Democrática que faça frente às propostas do "Programa"Escola sem Partido". Com essa finalidade, ele manifesta de forma clara e concisa, que uma Educação Democrática não pode ser limitada à uma qualificação para o trabalho, antes, precisa se opor às diversas formas de opressão que ocasionam o afastamento do alunado do ambiente escolar. Somado a isso, para se ter uma Educação que vise a Democracia, é fundamental a valorização dos profissionais da Educação, afinal, sem o diálogo entre docentes e discentes não há processo educacional.

No que tange a defesa do diálogo, é preciso mencionar, ainda, que ele se torna um importante aliado no combate ao discurso conservador, contribuindo para "construir politicamente a exclusão dos discursos de ódio e desrespeito aos direitos humanos" (PENNA, 2018a, p. 117). O caráter "dialogal" também é defendido por Freire (2018), ao sustentar que é através de uma relação horizontal que se origina uma matriz crítica e que surge a criticidade. Dito de outro modo, é somente pelo diálogo que há comunicação e que se faz Democracia.

Trazer o pensamento desses autores em diálogo, tem como premissa enriquecer, reiterar e enfatizar a luta por uma Educação Democrática. Cabe ressaltar, que os escritos de Paulo Freire não datam do ano de 2020, mas sua luta ressoa aos nossos dias, inspirando-nos a seguir. Sua mensagem e seu trabalho nos impulsionam a agir e a não desanimar, mesmo que tenhamos pela frente "tempos sombrios" (ARENDT, 2008) a enfrentar. 


\section{CONSIDERAÇÕES FINAIS}

A educação existe e se faz presente nas sociedades humanas, fora destas não há educação. De modo semelhante, não existem sujeitos no vazio e nem desconectados dos outros sujeitos. $\mathrm{O}$ objetivo deste texto era conduzir um alinhavar entre as reflexões de Freire (2018) e a nossa inquietação acerca da composição de uma Educação Democrática e possível, diante da proposição enrijecida e espinhosa do "Programa Escola sem Partido". Para alcançá-lo, trouxemos para o diálogo pensadores que, vivenciando a atual onda conservadora, focalizam a educação como um movimento amplo e, principalmente, humano, que não obedece a formas mecanicistas, tendenciosas e preconceituosas de pensar a sociedade e os sujeitos.

Chegamos, após este percurso, à alguns entendimentos finais. $\mathrm{O}$ primeiro reside na indicação de que as tentativas de limitar a educação e de impedir o desenvolvimento da conscientização dos sujeitos não começaram com o ESP. A própria argumentação freireana assinala indícios de um pensamento conservador preocupado com seus privilégios e interesses. Compelindo para a alienação de outros grupos, este pensamento promoveria uma distorção da realidade, tendo na educação, seu principal objeto.

A segunda conclusão que alcançamos compreende que, se proposições conservadoras não são fenômenos novos e nem distantes de nossa realidade, então a obra de Freire surge como uma potente lente para entendê-los, bem como, para vislumbrar os elementos que fazem da iniciativa do "Programa Escola sem Partido" uma concepção de educação impositora, fechada ao debate e que intenta moldar os sujeitos, sejam eles alunos ou professores.

Em consonância com a resolução anterior, inferimos que o projeto do ESP muito se assemelha a concepção bancária da educação. Em ambos os casos, temos a relação professor-aluno reduzida a transmissão-assimilação de conteúdos desvencilhados dos saberes, vivências e realidades dos sujeitos. Contudo, o ESP eleva o grau do caráter antidemocrático ao perseguir e propagar a denúncia a professoras e professores e a tratar o alunado como vítima de abusadores intelectuais.

Por fim, conversando com o objetivo deste trabalho e em resposta à nossa questão de partida, podemos concluir que, mediante a costura das ideias aqui expostas, a democracia é um caminho possível e realizável dentro e fora da escola. O amálgama entre Educação e Democracia, diante de proposições conservadoras de educação, expõe a diversidade de sujeitos, expressões e identidades plurais tão manifestas em nossa sociedade e que já estão presentes nas escolas. Depreendemos, portanto, que muitos docentes realizam esse amálgama em seu trabalho, valorizando o diálogo democrático e crítico, por isso se tornam uma ameaça à manutenção do pensamento conservador.

Uma Educação Democrática, pensada para o chão da escola, respeita todos aqueles que convivem e passam por esse espaço, questiona a realidade e desnaturaliza relações sociais, buscando a cidadania plena, crítica e dialógica. O pensamento de Paulo Freire contribui, assim, para cunharmos uma compreensão de Educação Democrática que enxerga na prática democrática e no ato educacional o espaço do negro, da mulher, do indígena, dos grupos LGBTQIA + e de tantos sujeitos plurais que precisam ter na Educação um lugar de pertencimento e de ação.

\section{REFERÊNCIAS}

ALMEIDA, Juniele Rabêlo. de; CALDAS, Renan Rubim. História Pública e Educação Democrática: "Professores contra o projeto Escola sem Partido" - Narrativas em debate. Revista Observatório, Palmas, v. 3, n. 2, p. 66-91, abr./jun. 2017. 
ALVES, Claudia. Problemas da relação educação-cidadania na história brasileira. In: FELGUEIRAS, Margarida Louro; VIEIRA, Carlos Eduardo (orgs.). Cultura escolar, migrações e cidadania. Porto: Sociedade Portuguesa de Ciências da Educação, 2010, p. 145-162.

ARENDT, Hannah. Homens em Tempos Sombrios. Tradução de Denise Bottmann. São Paulo: Companhia das Letras, 2008.

FIGUEIREDO, Ivanilda. Direitos Humanos e Estado laico. Relatório da Relatoria de Direitos Humanos e Estado Laico da Plataforma de Direitos Humanos - Dhesca Brasil, 2016.

DUNKER, Christian Ingo Lenz. Psicologia das massas digitais e análise do sujeito democrático. In: AUTORES, V. Democracia em risco? 22 ensaios sobre o Brasil de hoje. São Paulo: Companhia das Letras, 2019, p. 116-135.

FERNANDES, Florestan. O desafio educacional. São Paulo: Cortez \& Autores Associados, 1989.

FREIRE, Paulo. Educaşão como prática da liberdade. $44^{a}$ ed. Rio de Janeiro/São Paulo: Paz e Terra, 2018.

FREIRE, Paulo. Pedagogia do Oprimido. 69a ed. Rio de Janeiro/São Paulo: Paz e Terra, 2019, 256p.

FRIGOTTO, Gaudêncio. A disputa da educação democrática em sociedade antidemocrática. In: PENNA, Fernando de Araujo; QUEIROZ, Felipe; FRIGOTTO, Gaudêncio (orgs.). Educação democrática: antídoto ao Escola sem Partido. Rio de Janeiro: UERJ, LPP, 2018. p. 15-31.

PENNA, Fernando de Araujo. "Escola sem Partido" como ameaça à Educação Democrática: fabricando o ódio aos professores e destruindo o potencial educacional da escola. In: MACHADO, André Roberto.; TOLEDO, Maria Rita de Almeida (orgs.). Golpes na bistória e na escola: o Brasil e a América Latina nos Séculos XX e XXI. $1^{a}$ ed. São Paulo: Cortez: ANPUH SP - Associação Nacional de História. Seção São Paulo, 2017. p. 247-260.

PENNA, Fernando de Araujo. Construindo estratégias para uma luta pela educação democrática em tempos de retrocessos. In: PENNA, Fernando de Araujo; QUEIROZ, Felipe; FRIGOTTO, Gaudêncio (orgs.). Educação democrática: antídoto ao Escola sem Partido. Rio de Janeiro: UERJ, LPP, 2018a. p. 111-130.

PENNA, Fernando de Araujo. O discurso reacionário de defesa do projeto "Escola sem Partido": analisando o caráter antipolítico e antidemocrático. Quaestio, Sorocaba, SP, v. 20, n. 3, p. 567-581, dez. 2018b.

SEPUlVEDA, Denise; SEPUlVEDA, José Antonio. Conservadorismo e seus impactos no currículo escolar. Currículo sem Fronteiras, v. 19, n. 3, p. 868-892, set./dez. 2019.

- Material disponível na internet:

ESCOLA SEM PARTIDO. Site oficial. Disponível em: http://escolasempartido.org/ Acesso em 14 fev. 2020.

Submetido em agosto de 2020

Aprovado em fevereiro de 2022

\section{Informações da autora}

Hosana do Nascimento Ramôa

Doutoranda no Programa de Pós-Graduação em Educação na Universidade Federal Fluminense (PPGE/UFF) 
E-mail:hosana.nramoa@gmail.com

ORCID: https://orcid.org/0000-0002-8805-3953

Link Lattes: http://lattes.cnpq.br/1213288933572996 